\title{
Synthesis Growth, structural, optical, SHG and characterization a new organic potential novel material Z-scan studies third order nonlinear optical material on single crystal of $\mathrm{N}$-(tert-butyl)-2-(2-nitrophenyl) imidazo [1,2-a]Pyridin-3-amines
}

\author{
K.Elumalai Kuppan $^{1}$, K.Sakthiumurugesan ${ }^{2}$ \\ ${ }^{1}$ Department of physics, presidency college (Autonomous),Chennai, India \\ ${ }^{2}$ Department of physics, presidency college (Autonomous), Chennai, India
}

Corresponding author: elumalai9176@gmail.com

Available online at: www.isroset.org

Received 20/Dec/2017, Revised 14/Jan/2018, Accepted 25/Feb/2018, Online 30/Apr/2018

\begin{abstract}
In this work, an organic crystal, Synthesis of N-( tert-butyl)-2(2-nitrophenyl[1,2-a]Pyridin-3-amine, pdno2 single crystal were grown by slow evaporation solution growth method and the properties of the grown crystals were investigated . The formation of salt has been confirmed by single crystal X-ray diffraction and NMR Spectroscopic technique. The crystal structure was determined by single crystal $\mathrm{x}$-ray diffraction analysis and it belongs to monoclinic system with the space group c1 Fourier transform infrared spectral study has been carried out to confirm the presence of various functional groups, UV-VisNIR study showed that the pdno2 crystal has a wide transmission window with low near-UV cut off wavelength at $231 \mathrm{~nm}$. The UV-Vis-NIR transmission spectrum recorded to find the optical transmittance window and lower cut off wavelength of the salt crystal. Raman spectra correlate very well with the structural data and illustrated the sub title choice of the ligands used can affect the vibrational characteristics of the Mo-o bonds vibration modes were assigned using FT-IR and FT-Raman spectra. Mass spectroscopy transmittance studies revealed that the pdn02 crystal has a wide transmission range from 250to900 nm with the lower cut 0 f wavelength of $150 \mathrm{~nm}$. Thermal properties were investigated using TGA/DSC analyses .The thermal stability of the compound was investigated by carrying out TGA/DSC analyses simultaneously. The second harmonic generation in the crystal was confirmed by the modified Kurtz-perry powder test employing the Nd: YAG laser as the source for infrared radiation. Third order nonlinear optical properties nonlinear absorption coefficient, nonlinear refractive index and third order nonlinear susceptibility was calculated by Z-scan method using $632.8 \mathrm{~nm} \mathrm{He}-\mathrm{Ne}$ laser.
\end{abstract}

Keywords- crystal structure ,FTIR, Differential Scanning Calorimeter, Thermo gravimetric Analyses, NMR, Second Harmonic Generation, Third harmonic Generation, Raman Spectroscopy. UV-Vis -NIR Spectrum, Mass spectroscopy,

\section{INTRODUCTION}

Organic material systems have been extensively attracting candidate used in the synthesis of efficient second and TONLO materials due to its quick NLO response with the enhanced figure of merit. In this organic ionic crystals have lead high resolution because of its electro delocalization behaviors inherent facile flexibility second harmonic generation efficiency with large LDT s value wide optical transparency high . pdno2 is an important inorganic NLO crystal and it is successfully used for frequency conversion of laser radiation to the mass spectroscopy region. The application of NLO crystals is required in all frequency ranges but their demand in producing laser beams in UV visible regions is growing enormously pzno2 crystals are reliable materials for effective nonlinear process. Thermal stability FT-IR and FT-Raman mechanical thermal ,SGH and third order nonlinear optical properties of pdno 2 crystals .SGH materials are much warranted because of their potential application in the field materials was synthesized and the single crystals were grown and characterized through electronic, vibrational, absorptions, nuclear, magnetic resonance spectral studies and TGA/DSC and nonlinear optical studies. In this paper for the first time we report the synthesis, growth, structural and physical properties of the title crystal pyridine-3-amine.s

\section{EXPERIMENTAL PROCEDURE}

synthesis of $\mathrm{N}$-(tert-butyl)-2-(2-nitrophenyl)imidazol[1,2a]pyridine-3-aamine:pdno2 2-Nitro benzaldehyde (1mmol),2-Amino pyridine (1mmol0,tertiary Butyl isocyanide $(1 \mathrm{mmol})$ and ethanol $(8 \mathrm{ml})$ were added to $50 \mathrm{ml}$ RB flask. The reaction mixture was stirred at room temperature with catalytic amount of Iodine for about 24 hours. An orange -yellowish precipitate was formed check TLC in hexane: ethyl acetate (65:35) percentage used as eluting solvents. The precipitate was filtered off, washed 
with excess ethanol and dried under vacuum. Finally collected the precipitated and crystallized from ethanol to get $98 \%$ yield and check the further spectrum data analysis.

\section{Single crystal $\mathrm{X}$-ray diffraction analysis}

Single crystal of the compound suitable for X-ray diffraction was obtained by slow evaporation method. Three dimension intensity data were collected on a BRUKER8 SMART APEX CCD Diffractometer Using graphite Monochromatized MO-KX radiation $(\mathrm{x}=0.71073 \mathrm{~A})$ at Department of chemistry, IIT, Chennai, India. The structure was solved by direct methods and refined on F2 by fullmatrix least-squares procedures using the SHELXL programs9.All the non-hydrogen atoms were refined using isotropic and later anisotropic thermal parameters. The hydrogen atoms were included in the structure factor calculation at idealized positions by using a riding model, but not refined .Image were created with ORTEP-3.The crystallographic data for the compound are listed in table 1.The title crystal belongs to monoclinic crystallographic system with non-centrosymmetry space group.c1c1 .The unit cell parameters are $\mathrm{a}=16.0877(10) \mathrm{A}, \mathrm{b}=22.0452(13) \mathrm{A}$ ,c=17.8670(11) A,And volume $\mathrm{V}=6326.7(7) \mathrm{A}$. The intermolecular N-H-O,O-H-O,

And $\mathrm{C}-\mathrm{H}-\mathrm{O}$ type hydrogen bonds between the cationic and anionic Species help to create a delicate balance between the molecular and Super molecular charge transfer processes by creating a non-symmetry structure.

Table 1- Crystal data and structure refinement of pdn02

\begin{tabular}{|c|c|c|}
\hline Chemical formula & \multicolumn{2}{|l|}{$\mathrm{C}_{17} \mathrm{H}_{18} \mathrm{~N}_{4} \mathrm{O}_{2}$} \\
\hline Formula weight & \multicolumn{2}{|l|}{$310.35 \mathrm{~g} / \mathrm{mol}$} \\
\hline Temperature & \multicolumn{2}{|l|}{$296(2) \mathrm{K}$} \\
\hline Wavelength & \multicolumn{2}{|l|}{$0.71073 \AA$} \\
\hline Crystal size & \multicolumn{2}{|c|}{$0.100 \times 0.220 \times 0.250 \mathrm{~mm}$} \\
\hline Crystal habit & \multicolumn{2}{|c|}{ clear light yellow Rectangular } \\
\hline Crystal system & \multicolumn{2}{|c|}{ Monoclinic } \\
\hline Space group & \multicolumn{2}{|l|}{ C 1 c 1} \\
\hline \multirow[t]{3}{*}{ Unit cell dimensions } & $\mathrm{a}=16.0877(10) \AA$ & $\alpha=90^{\circ}$ \\
\hline & $\begin{array}{l}\mathrm{b}=22.0452(13) \\
\AA\end{array}$ & $\begin{array}{l}\beta \\
93.213(4)^{\circ}\end{array}$ \\
\hline & $\mathrm{c}=17.8670(11) \AA$ & $\gamma=90^{\circ}$ \\
\hline Volume & $6326.7(7) \AA^{3}$ & \\
\hline $\mathrm{Z}$ & \multicolumn{2}{|l|}{16} \\
\hline Density (calculated) & \multicolumn{2}{|l|}{$1.303 \mathrm{~g} / \mathrm{cm}^{3}$} \\
\hline $\begin{array}{l}\text { Absorption } \\
\text { coefficient }\end{array}$ & \multicolumn{2}{|l|}{$0.089 \mathrm{~mm}^{-1}$} \\
\hline $\mathrm{F}(000)$ & \multicolumn{2}{|l|}{2624} \\
\hline
\end{tabular}

\begin{tabular}{|l|l|}
\hline $\begin{array}{l}\text { Theta range for data } \\
\text { collection }\end{array}$ & 1.57 to $25.00^{\circ}$ \\
\hline Index ranges & $\begin{array}{l}-19<=\mathrm{h}<=19,-26<=\mathrm{k}<=24,- \\
21<=1<=21\end{array}$ \\
\hline
\end{tabular}

\begin{tabular}{|c|c|c|}
\hline Reflections collected & \multicolumn{2}{|l|}{25500} \\
\hline Independent reflections & \multicolumn{2}{|c|}{$9616[\mathrm{R}($ int $)=0.0414]$} \\
\hline $\begin{array}{l}\text { Coverage of } \\
\text { independent reflections }\end{array}$ & \multicolumn{2}{|c|}{$99.9 \%$} \\
\hline Absorption correction & \multicolumn{2}{|l|}{ multi-scan } \\
\hline $\begin{array}{l}\text { Max. and min. } \\
\text { transmission }\end{array}$ & \multicolumn{2}{|c|}{0.9910 and 0.9780} \\
\hline Refinement method & \multicolumn{2}{|c|}{ Full-matrix least-squares on $\mathrm{F}^{2}$} \\
\hline Refinement program & \multicolumn{2}{|c|}{$\begin{array}{l}\text { SHELXL-2014/7 ( Sheldrick, } \\
\text { 2014) }\end{array}$} \\
\hline Function minimized & \multicolumn{2}{|c|}{$\Sigma \mathrm{w}\left(\mathrm{F}_{\mathrm{o}}^{2}-\mathrm{F}_{\mathrm{c}}^{2}\right)^{2}$} \\
\hline $\begin{array}{l}\text { Data / restraints / } \\
\text { parameters }\end{array}$ & \multicolumn{2}{|c|}{$9616 / 2 / 841$} \\
\hline Goodness-of-fit on $\mathrm{F}^{2}$ & \multicolumn{2}{|l|}{1.488} \\
\hline$\Delta / \sigma_{\max }$ & \multicolumn{2}{|l|}{3.006} \\
\hline \multirow[t]{2}{*}{ Final $\mathrm{R}$ indices } & $\begin{array}{l}3413 \text { data; } \\
\mathrm{I}>2 \sigma(\mathrm{I})\end{array}$ & $\begin{array}{l}\mathrm{R} 1=0.0443 \\
\mathrm{wR} 2=0.0684\end{array}$ \\
\hline & all data & $\begin{array}{l}\mathrm{R} 1=0.1487 \\
\mathrm{wR} 2=0.0857\end{array}$ \\
\hline Weighting scheme & \multicolumn{2}{|c|}{$\begin{array}{l}\mathrm{w}=1 /\left[\sigma^{2}\left(\mathrm{~F}_{\mathrm{o}}^{2}\right)\right] \\
\text { where } \mathrm{P}=\left(\mathrm{F}_{\mathrm{o}}^{2}+2 \mathrm{~F}_{\mathrm{c}}^{2}\right) / 3\end{array}$} \\
\hline $\begin{array}{l}\text { Absolute structure } \\
\text { parameter }\end{array}$ & \multicolumn{2}{|c|}{$2.2(10)$} \\
\hline $\begin{array}{l}\text { Largest diff. peak and } \\
\text { hole }\end{array}$ & \multicolumn{2}{|c|}{0.402 and $-0.385 \mathrm{e}^{-3}$} \\
\hline $\begin{array}{l}\text { R.M.S. deviation from } \\
\text { mean }\end{array}$ & \multicolumn{2}{|l|}{$0.044 \mathrm{e}^{\circ}{ }^{-3}$} \\
\hline
\end{tabular}

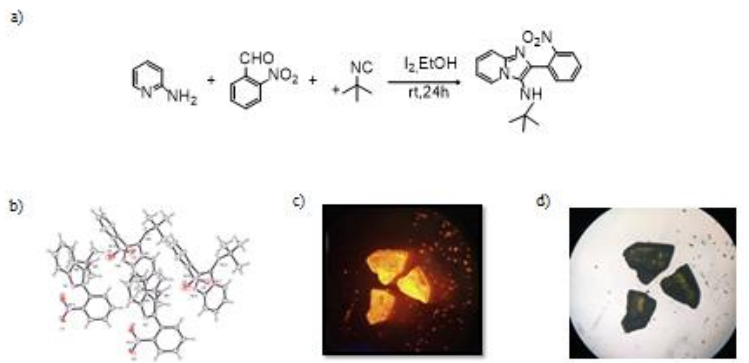

Figure 1.a) Reaction scheme, b) ORTEP view of crystal c) Crystal in Xenon lamp d) Crystal in ordinary light

\section{FT-IR Spectral data}

FT-IR $\left(\mathrm{cm}^{-1}\right)$

Assignment

obo deformation

781.19

B-o-ring

stretching

990.83

stretching
B-o-ring 
963.48

B-o-ring

stretching

1149.42

inplane bending

1204.18

vibration

1273.43

B-O-vibrations

1366.66

stretching

2972.09

stretching vibration

3247.42

stretching vibration of

$\mathrm{COOH}$ group

\section{FT-IR spectral data}

FT-IR (cm-1)

Assignment

418.49

deformation

781.19

990.83

963.48

1149.42

1204.18

1273.43

1366.66

2972. 09

3247.42

Aromatic C-H

vibration.

C-N-stretching

B-O-asymmetric

C-H-Asymmetric

$\mathrm{O}-\mathrm{H}$ symmetric

obo

C-Cl stretch

$=\mathrm{C}-\mathrm{H}$ stretch

$=\mathrm{C}-\mathrm{H}$ stretch

C-N stretch

C-N stretch

C-N stretch

C-H rock

C-H stretch

N-H stretch

FT-IR

The FT-IR spectrum is recorded in the range $400-4000 \mathrm{~cm}-1$ by perkin - Elmer spectrometer .FT-IR spectrum of 2pdno2 is given in figure OBO deformation is assigned to 418.49 $\mathrm{cm}-1$ and $781.19 \mathrm{~cm}-1 \mathrm{~B}-\mathrm{O}-\mathrm{ring}$ stretching, $990.83 \mathrm{~cm}^{-1} \mathrm{~B}-\mathrm{O}-$ ring

stretching $1149.42 \mathrm{~cm}$ AromaticCHinplanebendingvibratio120 $4.18 \mathrm{cmstretchingvibration} 1273.43 \mathrm{c} 1 \mathrm{CHvibrations} 1366.66 \mathrm{c}$ m1 B-O-Asymmetricstretching, $2972.09 \mathrm{~cm}-1 \quad$ C-Hasymmetric stretching vibration $3247.42 \mathrm{~cm}-1$ O- HSymmetric stretching vibration of $\mathrm{COOH}$ group. The FT-IR spectrum of NBS was recorded in the range $400-4000 \mathrm{~cm}-1$ the frequency at which a specific group absorption is independent on its electron environment with in the molecule and its physical state.

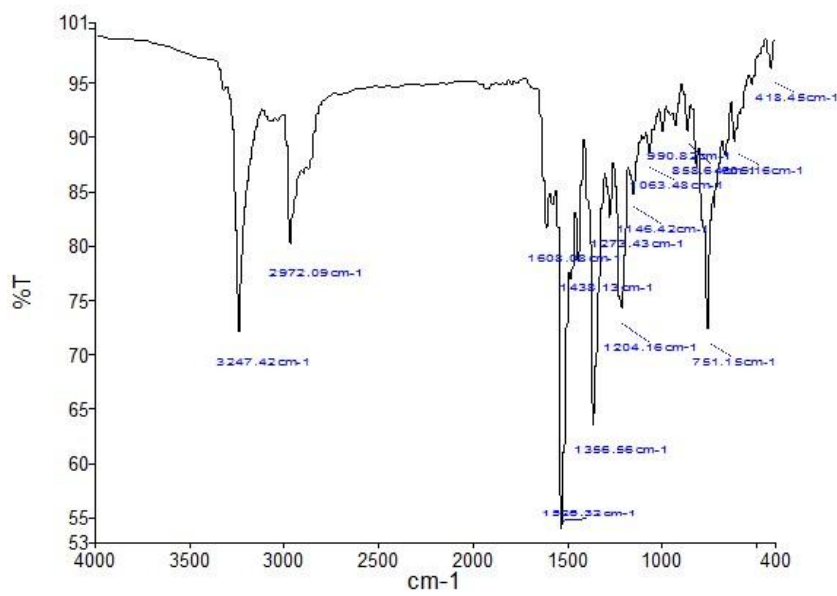

Figure 2 FT-IR Spectrum of pdn02

\section{NMR Spectral data}

\$ value(ppm)

Assignment

149.49

C3 carbon of 3nitro anilinium moiety.

142.39

C1 carbon of 3-

carboxyl anilinium moiety.

132.81

C4 carbon of 3nitro anilinium moiety.

132.38

C4 carbon of 3 nitro anilinium moiety

C6 carbon of 3-

128.36

carboxyl anilinium moiety

124.35

C2 carbon of 3 nitro anilinium moiety

124.23

C2 carbon of 3 nitro anilinium moiety

C4 carbon $\mathrm{p}-$

123.33

toluene sulfonate moiety.

117.69

C6 carbon 0f 3 - 


\subsection{5}

C1 carbon of 3-

nitro anilinium

\section{NMR spectral studies}

The carbon signal at $\$ 150 \mathrm{ppm}$ is attributed to the cholorin substituted . The ${ }^{1} \mathrm{H}$ NMR spectrum of $\mathrm{pdno}_{2}$ crystal is shown in figure2. The intense singlet signal appearing at $2.8 \mathrm{ppm}$ is due the three methyl protons of p-toluene sulfonate moiety in the crystal . The $\mathrm{C}_{3}$ and $\mathrm{C}_{4}$ aromatic protons of the same kind in the same moiety exihibit a doublet centeredat7.8ppmthecomplex multipled appearing from 8.0 to $8.2 \mathrm{ppm}$ is attributed to the $\mathrm{C}_{4}$ and $\mathrm{c}_{6}$ aromatic protons in the same chemical environment in 3-carboxyl anilinium moiety. The $\mathrm{C}_{2}$ aromatic proton of 3-carboxyl anilinium moiety stands responsible. for the singlet signal at $8.06 \mathrm{ppm}$ the multipled signal appearing from $8.6 \mathrm{ppm}$ to8.8ppm has been assigned to $\mathrm{C}_{5}$ aromatic proton of the same moiety. The appearance of six distinct proton signals confirms the molecular structure Of the salt crystal. In the $1 \mathrm{H}$ NMR Spectrum figure Two doublets at $8.2 \mathrm{ppm}$ and 8.0ppm are due to to the $\mathrm{C}_{4}$ and $\mathrm{C}_{6}$ aromatic protons of the 2-nitrophenyl moiety respectively The triplet centered at $7.8 \mathrm{ppm}$ is attributed to $\mathrm{C}_{5}$ aromatic proton of the 2nitrophenyl moiety. The $\mathrm{C} 4$ aromatic proton of 1,2 a pyridine moiety appears as a singlet at $6.8 \mathrm{ppm}$. The appearance of eleven distinct carbon signals in the $13 \mathrm{c}$ spectrum [fig] explicity confirms the molecular structure. In the down field two carbon signal 149.49 and 142.39ppmowe to the highly dehielded $\mathrm{C}_{1}$ and

$\mathrm{C}_{2}$ carboxyl carbons of the nitrophenyl moiety. The signal at 136.19 is assigned to the C3 carbon in the same moiety .The carbon signal149.49and142.39ppm owe to the highly dehielded $\mathrm{C}_{1}$ and $\mathrm{C}_{2}$ carboxyl carbons of the nitrophenyl moiety. The signa136.19 is assigned to the $\mathrm{C} 3$ carbon in the same moiety .The carbon signal $132.81 \mathrm{ppm}$ is due to the $\mathrm{C}_{1}$ and $\mathrm{C}_{3}$ carbons of the same kind in 1,2 a pyridine moiety. The signal at $128.36 \mathrm{ppm}$ is attributed $\mathrm{S}$ of the $\mathrm{C} 6$ carbon of the 1,2 a nitrophenyl moiety .The signal appearing at $132.38 \mathrm{ppm}$ is attributed to the $\mathrm{C}{ }_{5}$ carbon of 1,2 a nitrophenyl moiety .The signal at $149.49,132.81$, and 142.39ppm owe to the C1,C4and c2 carbons of 1,2 a nitrophenyl. moiety espectively. The carbon of $132.81 \mathrm{ppm}$ owes to two methyl carbon atoms .

${ }^{1} \mathrm{H}$ NMR $\left(400 \mathrm{MHz}, \mathrm{CDCl}_{3}\right) \delta 8.19(\mathrm{~d}, J=6.9 \mathrm{~Hz}, 1 \mathrm{H}), 7.91$ $(\mathrm{dd}, J=8.1,1.1 \mathrm{~Hz}, 1 \mathrm{H}), 7.82(\mathrm{dd}, J=7.7,1.3 \mathrm{~Hz}, 1 \mathrm{H}), 7.70$ $-7.61(\mathrm{~m}, 1 \mathrm{H}), 7.59-7.44(\mathrm{~m}, 2 \mathrm{H}), 7.16$ (ddd, $J=9.0,6.7$, $1.3 \mathrm{~Hz}, 1 \mathrm{H}), 6.80(\mathrm{td}, J=6.8,1.1 \mathrm{~Hz}, 1 \mathrm{H}), 2.77(\mathrm{~s}, 1 \mathrm{H}), 0.96$ (s, 9H).

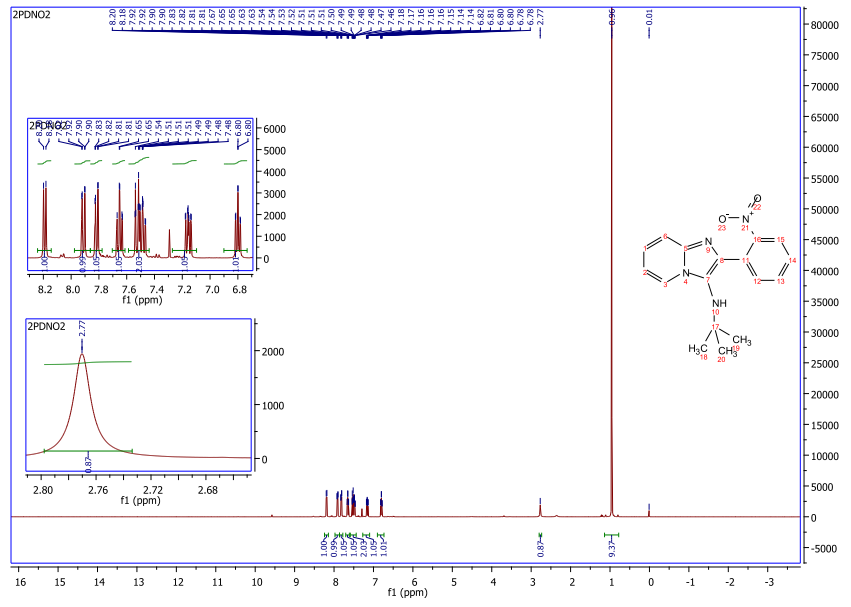

Figure 3a NMR spectrum of pdno2

${ }^{13} \mathrm{C}$ NMR (101 MHz, $\left.\mathrm{CDCl}_{3}\right) \delta 149.49,142.39,136.19$, $132.81,132.38,128.36,124.35,124.23,123.33,117.69$, $111.75,77.40,77.08,76.76,55.61,30.04$

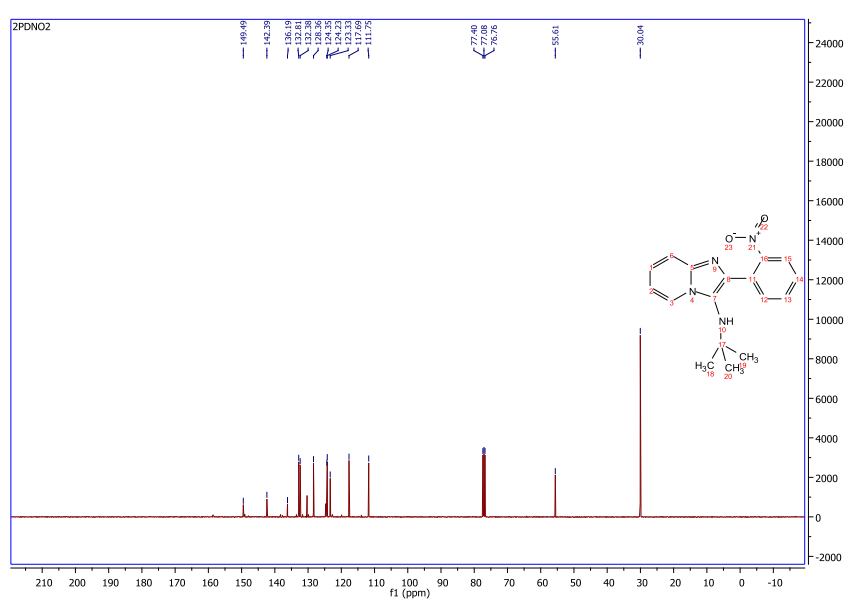

Figure $3 \mathrm{~b}$ NMR spectrum of pdno2

\section{Mass Spectroscopy}

The lower cut-off wavelength and high optical transparency up to near infrared region are crucial parameters for an optical material. Mass spectroscopy spectrum was recorded within the range of 200-1100nm using the using lower cutoff at $300 \mathrm{~nm}$ combined with very good transparency attest the usefulness of this material for optoelectronic applications and the generation of pdno2 . 


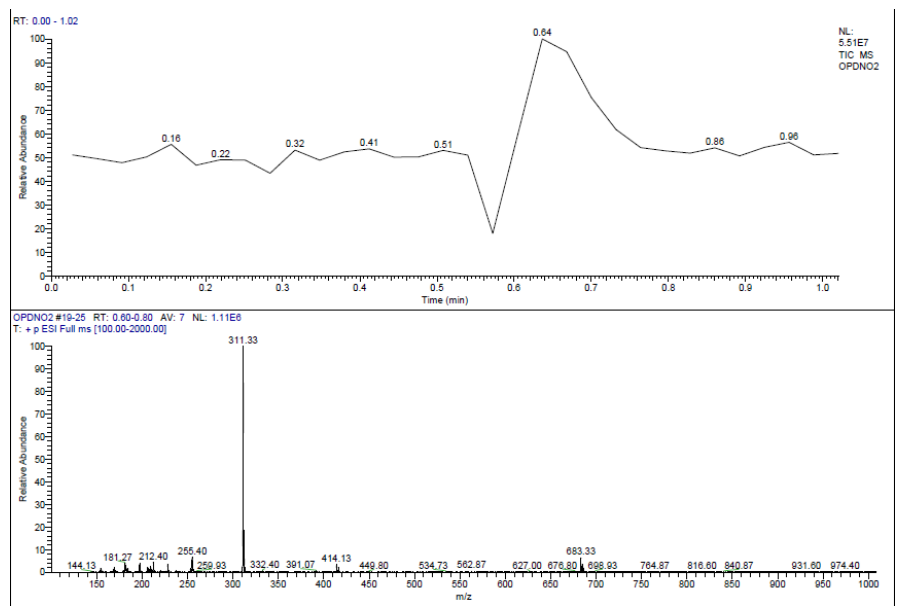

Figure 4a Mass spectroscopy of pdno2

\section{UV SPECTRUM}

The UV-Vis-NIR Transmission spectrum of pdno 2 crystal is shown in fig. $4 \mathrm{~b}$.The attained percentage of transmission was $45 \%$ in the visible region, as has been observed in the spectrum there is no significant absorption in the entire visible region and near infrared region. The lower wavelength cut-off is around $400 \mathrm{~nm}$ The crystal has a wide transparency window in the visible and NIR regions up to $2500 \mathrm{~nm}$. This wide transparency window enables the title crystal to be a potential candidate for the optical

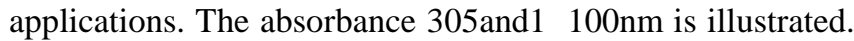
above $200 \mathrm{~nm}$ and absorbance due to electronic transition between 305 to $1100 \mathrm{~nm}$. This less absorbance in the entire visible and near-IR region is an important requirement for NLO applications. The UV -Vis -NIR Spectral study was carried out using a T 90+PG instruments spectrophotometer A optically transparent crystal with $1.2 \mathrm{~mm}$ thickness was used for this study The pdno2 crystal has sufficient transmittance in the entire visible, near UV and IR regions and has good transparency about 60\% (fig.4b).The power cut-off wavelength of pdno 2 of was found to be $231 \mathrm{~nm}$ and the absorption is due to the promotion of an electron from a 'non-bonding' (lone-pair) n-orbital to an 'anti-bonding' \#orbital designed as \#* ( $\left.\mathrm{n}_{-} \#^{*}\right)$. The absorption coefficient (a)was estimated from the transmission spectrum based on the following relation. $435 \mathrm{~nm}$ and $295 \mathrm{~nm} \mathrm{EtOH}$ solvent used $10 \mathrm{uM}$ concentration sample per $\mathrm{mL}$

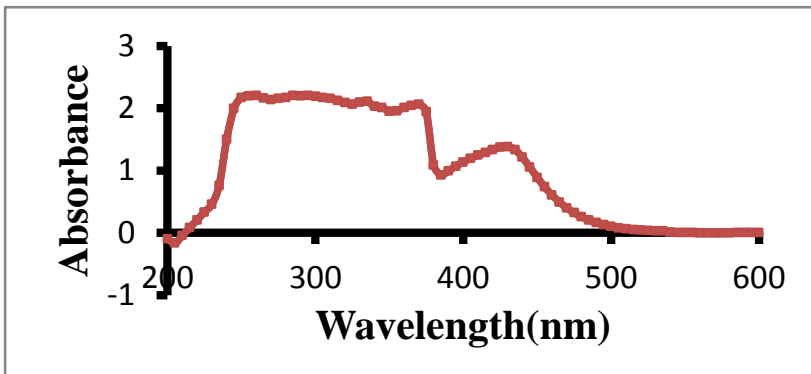

pdno2

Figure 4b UV-Vis-NIR Spectrum of

TGA

\section{Thermo gravimetric Analysis}

\section{Thermal studies}

Thermal analysis was performed on the grown crystal to study the thermal stability and melting point. The thermo gravimetric analysis of LHFFA was carried out between room temperature $\left(28^{\circ} \mathrm{c}\right)$ and $1200^{\circ} \mathrm{C}$ heating rate $20^{\circ} \mathrm{c} / \mathrm{min}$ in nitrogen atmosphere using SDT Q6000 V8.2 Built 100 thermal analyser. The TGA And measurements show the mass variation recorded during the heating. The results are shown in figure .The obtained TGA curve shows sudden weight loss at $221.47^{\circ} \mathrm{c}$ A powered sample weighing $24 \mathrm{mg}$ was used for the analyses. The analyses were carried out simultaneously in air at a range of 1-100c and are represented in fig. the thermo gravimetric analysis shows that the sample has good thermal stability up to $180^{\circ} \mathrm{c}$. The absence of water of crystallization in the molecular structure is indicated the absence of weight loss around $100^{\circ} \mathrm{c}$ and .Further there is no decomposition up to up to the melting point. The material decomposes at $221.47^{\circ} \mathrm{c}$ which is represented by the structure of loss of the mass. Above $221.47^{\circ} \mathrm{c}$ the material undergoes irresverable endothermic transition at $309.42^{\circ} \mathrm{c}$ The thermo gravimatric (tg) were carried out in a nitrogen atmosphere from temperature to $773 \mathrm{k}$. The decomposition occurs in two stages .The first stage incurred weight loss $17.22 \%$ at $309.42^{\circ} \mathrm{C}$ and the second stage of $94.95 \%$. The sharp exothermic peak $221.47^{\circ} \mathrm{C}$ corresponds to the melting point of the substance The absence of water of crystallization in the molecular structure is indicated by the absence of weight loss around $100 \mathrm{c}$ further there is no decomposition up to the melting point. The material decomposes at 228. 29c which represented by the students of loss of the mass. above $228.29 \mathrm{c}$ the material undergoes irrversible endothermic trasition at 338.99.The differential scanning calorimeter (dsc) is carried out using SDT Q290 v23.10 build 79 analyzer between 50 and $300 \mathrm{c}$ in the nitrogen atmosphere at a heating rate of $50 \mathrm{c} / \mathrm{min}$ and its shown in figure. In the 
DSC the endothermic peak observed near 300c corresponds to melting and the deuteration content of the synthesized material prior to the growth of DGPI was examined though differential scanning calorimeter (dsc) analysis . The sharp endothermic peak at $276.67 \mathrm{c}$ (figure) reveals that the starting material was not fully deuterated after the completed of the growth ,the dielectric measurements were carried out in order to understand the phase trasition temperature which is the direct evidence of the in corporation of the deutration regions of negative $\mathrm{v}(\mathrm{r})$ are usually associated with the long pair of electro negative atoms. As can be seen from the MEP map of the title crystal which regions having the negative potential are over the electro 'negative at(nitrogen and oxygen atoms)the regions having the positive potential are over the hydrogen atoms from this result. we can say that the $\mathrm{H}$ atom a indicate the strongest attraction and $\mathrm{o}$ atom indicate the strongest repulsion.

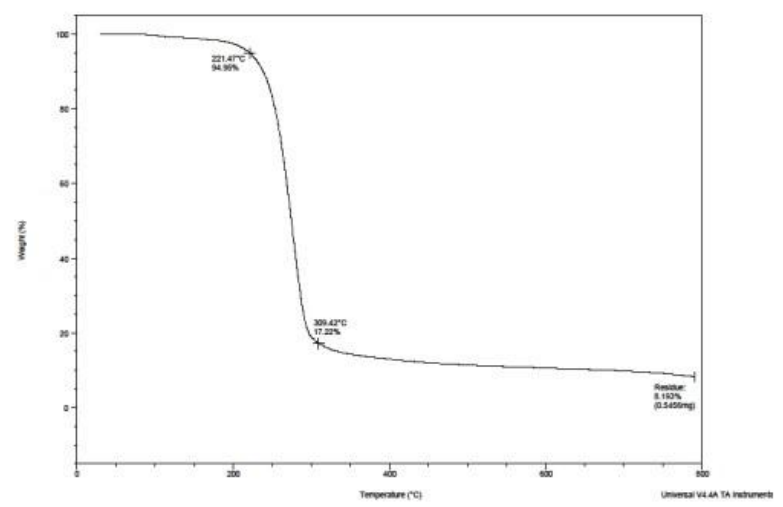

Figure 5 Thermo gravimetric analysis curve of pdno2

\section{SECOND HARMONIC GENERATION}

The output from Q-switched Nd: YAG laser $(\lambda=1064 \mathrm{~nm})$ model GCR-2 (10) Was focused on the powered GOX sample .Pulse energy was $5 \mathrm{MJ} / \mathrm{S}$ with pulse width of about 10ns. A bright green flash emission from the GOX sample was observed which indicates the NLO behaviour of the material .The second harmonic generation efficiency of Gox was compared with $\mathrm{pdno}_{2}$.The SHG output of $\mathrm{pdno}_{2}$ was $240 \mathrm{mv}$ and Gox had $210 \mathrm{mv}$ at given pulse energy of $5 \mathrm{MJ} / \mathrm{S}$. The SHG property of $\mathrm{pdn}_{2}$ is determined by the midified version of powder technique by Kurtz and perry. The fundamental beam of $\lambda=1064 \mathrm{~nm}$ from Q-switched $\mathrm{Nd}$ : YAG laser is used to test the SHG property of the grown crystals. The input pulse energy $1.6 \mathrm{MJ} /$ pulse is used pdn0 ${ }_{2}[150 \mathrm{~nm}]$ is used as the reference material $\mathrm{SHG}$ of $\mathrm{pdno}_{2}$ is measured as $135 \mathrm{mv}$ which is 0.9 times that of $\mathrm{pdno}_{2}$. The SHG behaviour of the title crystal was confirmed from the green light emission.

\section{Third order nonlinear optical properties}

The third order nonlinear refractive index and the nonlinear absorption coefficient were evaluated by the $\mathrm{z}$ scan measurements. In this method the sample is translated in $\mathrm{z}$ direction along the axis of a focused gaussian beam from the He-Ne laser at $\lambda=632.8 \mathrm{~nm}$ and the far field intensity is measured as a function of the sample position. It allows the simultaneous measurements of both the nonlinear refractive index and the nonlinear absorption coefficient .non-linear refractive index $n_{2}$ was calculated by the relation

$$
\begin{array}{r}
\mathrm{n}_{2}=\wedge \emptyset \\
\mathrm{KI}_{\mathrm{o}} \text { left }
\end{array}
$$

where $\mathrm{k}$ is wave vector, Io is intensity of the laser beam at focus $(z=0)$ left is affective thickness of the material and $\wedge \emptyset$ is phase shift.

The nonlinear absorption coefficient was estimated from the open aperture $\mathrm{z}$-scan data using the relation.

$$
\beta=2 \sqrt{2 x T}
$$

Io left

where $\boldsymbol{\Delta} \mathrm{T}$ is one valley value at open aperture $\mathrm{z}$-scan curve .The read and imaginary parts of the third order nonlinear susceptibility are defined as,

$$
\underset{{ }^{4} \operatorname{EO~c}^{2} \operatorname{no}^{2 \wedge} \emptyset}{\operatorname{Re} X^{(3)}}=\underline{10^{-}}
$$

$\pi$

$$
\underline{\mathrm{EO} \mathrm{c}^{2} \mathrm{no}^{2} \mathrm{I}_{\beta}}(\mathrm{x})^{3}=\underline{10^{-2}}
$$

$$
-4 \pi^{2}
$$

where $\underline{\epsilon O}$ is premitivity of the vacuum, no is linear refractive index of the material and $\mathrm{c}$ is velocity of light $\mathrm{X}$ (3) $=\sqrt{ }\left[\operatorname{Re}\left(\mathrm{X}^{(3)}\right]^{2}+\left[\operatorname{lm}\left(\mathrm{x}^{(3)}\right]^{2} \quad\right.\right.$ closed aperture and open aperture $\mathrm{z}$-scan curves are given in fig. from the closed aperture $\mathrm{z}$-scan measurements, the nonlinear refractive index was calculated as $0.760335 * 10-^{9} \quad \mathrm{~cm}{ }^{2} / \mathrm{W}$. The positive value of nonlinear refractive index shows that the crystal has a self-focusing nature, open aperture $\mathrm{z}$-scan measurements concluded that the nonlinear absorption coefficient of the mat erial is $-0.06311257 * 10^{-4} \mathrm{Cm} / \mathrm{W}$ .The third order nonlinear susceptibility $\mathrm{x}{ }^{(3)}$ was calculated as $1.259459 * 10^{-3}$ esu . The calculated third order nonlinear optical values of pdno2. 


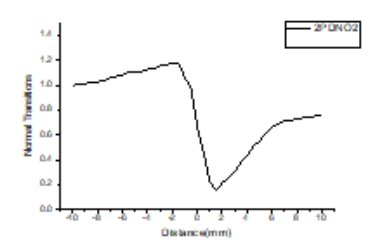

Figure 5a:Z-scan of closed curve

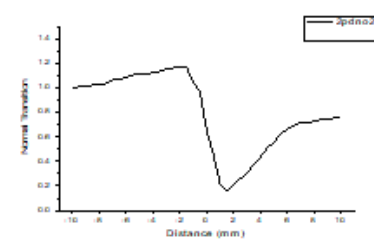

Figure 5c: Z-scan of Ratio curve

Figure 6 Z-scan Third order nonlinear optical properties

THIRD ORDER NON-LINEAR OPTICAL VALUES OF PDNO

Non-linear Refractive index

non-linear

absorption coefficient $(\mathrm{cm}$

$\left.\mathrm{n} 2(\mathrm{~cm} 2 / \mathrm{w}) 8.041 * 10^{-8} / \mathrm{w}\right) 0.015 * 10-4$

Real part of susceptibility Re Imaginary part of susceptibility Im

$$
\mathrm{X}(3)(\mathrm{esu}) 2.107 * 10-6 \quad \mathrm{X}(3) \text { (esu) } 0.094 * 10-6
$$

Third order susceptibility $\quad \mathrm{X}(3)$ (esu) $1.017 * 10-3$

$\mathrm{x} 3$ values of some NLO crystals

crystal

$\mathrm{x}(3)$ (esu)

$\mathrm{PdnO}_{2}$

$2.109 * 10-4$

He-Ne laser $(5 \mathrm{mw})$ source of wavelength $(\lambda=632.8 \mathrm{~nm})$ with the beam diameter of $0.5 \mathrm{~mm}$ was used for the Z-scan experiment . The gaussian input laser beam generated by focusing via Gaussian filter was projected through a convex lens placed at a focal length of $30 \mathrm{~mm}$ in transverse mode operation. High power laser damage tolerance factor decides the performance of an optical material to be employed in laser power related device applications.

z-scan

He-Ne laser $(5 \mathrm{mw})$ source of wavelength $(\lambda=632.8 \mathrm{~nm})$ with the beam diameter of $0.5 \mathrm{~mm} \quad$ was used for the $\mathrm{Z}$ -
Scan experiment the Gaussian input laser beam generated by focusing gausssian filter was projected through a convex lens placed at focal length of $30 \mathrm{~mm}$ in transverse mode operation High power laser damage tolerance factor decides the performance of an optical material to be employed in laser power related device applications .LDT measurements was performed on (020)facet of grown BCFF crystal using laser $(\lambda=1064 \mathrm{~mm})$ source .The laser beam of $1 \mathrm{~mm}$ diameter and pulse width of $10 \mathrm{~ns}$ with the frequency rate of $10 \mathrm{HZ}$ was used in this experiment .The damage occurred of the surface of the crystal placed at a focal length of $30 \mathrm{~cm}$ due to laser irradiation and its energy density was measured using a power meter (model NO:EPM 2000). The LDT value can be calculated using the expression.

\section{Differential Scanning Calorimeter}

The differential scanning calorimeter (dsc) is carried out using SDT Q290 v23.10 build 79 analyzer between 50 and $300^{\circ} \mathrm{c}$ in the nitrogen atmosphere at a heating rate of 50 ${ }^{\circ} \mathrm{c} / \mathrm{min}$ and its shown in figure 6 in the DSC the endothermic peak observed near $300^{\circ} \mathrm{c}$ corresponds to melting and the deuteration

content of the synthesized material prior to the growth of DGPI was examined though differential scanning calorimeter (dsc)analysis . The sharp endothermic peak at $276.67{ }^{\circ} \mathrm{c}$ (figure ) reveals that the starting material was not fully deuterated after the completed of the growth ,the dielectric

measurements were carried out in order to understand the phase trasition temperature which is the direct evidence of the in corporation of the deutration regions of negative $\mathrm{v}(\mathrm{r})$ are usually associated with the lone pair of electro negative atoms. As can be seen from the MEP map of the title crystal which regions having the negative potential are over the electro'negative atoms (nitrogen and oxygen atoms)the regions having the positive potential are over the hydrogen atoms from this result. we can say that the $\mathrm{H}$ atom a indicate the strongest attraction and o atoms indicate the strongest repulsion. 


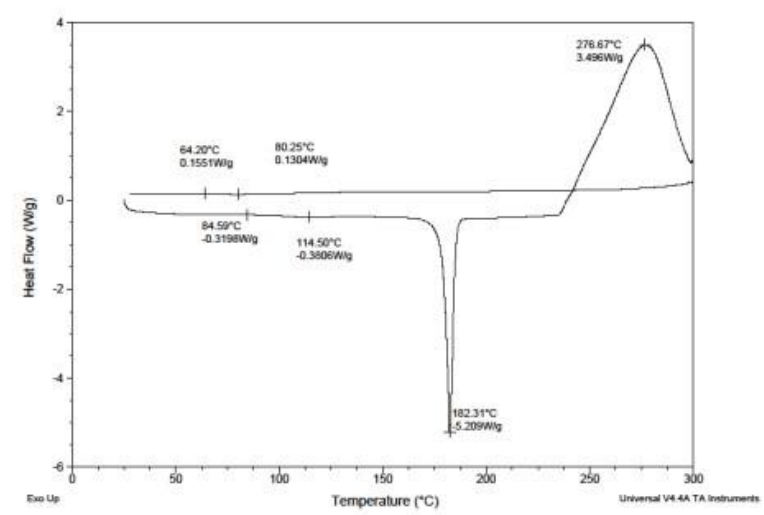

Figure 7 differential scanning calorimeter curve pdno2

\section{RAMAN SPECTROSCOPY:}

Raman spectrum of pdno $_{2}$ crystal are recorded using BRUCKER RFS 27 FT-Raman spectrometer with $\mathrm{Nd}: Y A G$, laser $(\lambda=1064 \mathrm{~nm})$ sample was scanned over the range of $500-400 \mathrm{~cm}-1$. The recorded FT-Raman spectrum is shown in figure peak observed for a given energy of the laser beam, the strength of Raman scattering depends on (frequency) and it was for this reason that lasers in the highfrequency, visible end of the spectrum were formely used. more recently, however ,near-infra-red laser excitation has been successful, usually using NdYAG laser operating at $9398 \mathrm{~cm}-1$.An added economy is that ,once the optical path of the FT spectrometer has been properly aligned, it is a fairly simple matter to interchange sources, beam slitters and detectors, and a single FT instrument can thus be operated either as an infra-red spectrometer or as A Raman spectroscopy In this section we shall discuss some examples of the combined use of Raman and infra-red spectroscopy to determine the shape of some simple molecules be limited and the molecules considered $(\mathrm{CO} 2, \mathrm{~N} 2 \mathrm{o}$, Clf3)have been chosen to illustrate the principles used; extension to other molecular types should be obvious. details first with the triatomic AB2 molecules types should be decided are whether each molecule is linear or not and ,if linear, whether it is symmetrical (B-A-B) or asymmetrical (B-B-A). in the case of carbon dioxide and nitrous oxide ,both molecules give rise to some infra-red bands with PR contours; they must, therefore, be linear. The mutual exclusion rule shows that $\mathrm{C} 02$ has a center of symmetry (O-C-0)while N2Ohas $\operatorname{not}(\mathrm{N}-\mathrm{N}-\mathrm{O})$,since only the latter has bands common to both its infra-red and Raman spectra, Thus the structures of these molecules are completely determined. When a beam of light is passed through a transparent substance ,a small amount of the radiation energy is scattered, the scattering persisting even if all dust particles or other extraneous matter are rigorously excluded from the substance. If monochromatic radiation ,or radiation of a very narrow frequency band, is used ,the scattered energy will consist almost entirely of radiation of the incident frequency (the so-called Rayleigh scattering)but, in addition, certain discrete frequencies above and below that of the incident beam will be scattered ;it is this which is referred to as Raman scattering. The symmetric modes of vibration are parallel and Raman polarized.

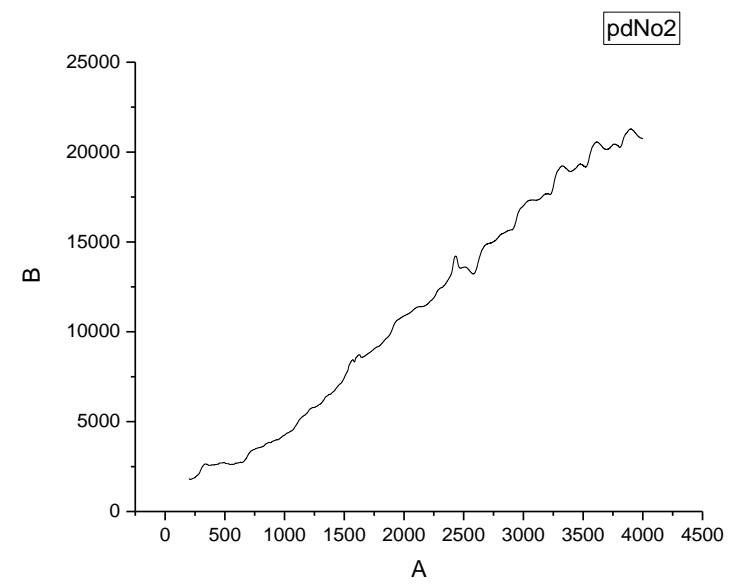

Figure 8 Raman spectroscopy of crystal pdno 2

\section{CONCLUSION}

The molecular structure was established by single crystal XRD analysis and further confirmed by NMR spectroscopic study. The presence of various functional groups in the title salt has been confirmed by FT-IR spectrometer Study. These crystals were subjected into various characterizations. single crystal XRD analysis shows that pdno2 crystal belong to triclinic crystal system with lattice parameters $\mathrm{a}=16.08779(10) \quad \mathrm{A}, \quad \mathrm{b}=22.0452(13) \mathrm{A}, \mathrm{C}=17.8670(11) \mathrm{A}$. Single crystal X-ray studies confirmed the cell parameters of pdn02 crystal. which can be employed in the NLO Applications in the entire visible region. In mass spectroscopy spectral analysis, the cut off wavelength was found to be $456 \mathrm{~nm}$. and the near IR region. UV -Vis The studies shows that it has a wide range of transparency region(second order NLO studies show that the pdn02 crystals can be used for the nonlinear properties. The relative SHG efficiency of pyridin-3-amine was found to be 1.34 times that of standard pdno 2 crystal. The functional groups are assigned using FT-IR and FT-Raman spectroscopy. The UV-Visible spectrum reveals that the grown Thermo have the gravimetric and differential thermal analysis shows that the crystal is stable up to 200c. The order nonlinear optical properties are calculated using $\mathrm{Z}$

scan technique. Deuteration content of the as grown crystals perfection analysis reveals that the quality of the 
grown was good without any internal structural boundaries. The recorded FT-IR spectrum confirms the presence of various functional groups as well as existence of intermolecular hydrogen bonding between the constituent species. The thermal behaviour of the grown crystal was studied by TGA-DSC analyses. The single and multiple shorts laser damage threshold values and the relative SHG efficiency of pzn02 were found out.

\section{REFERENCES}

[1]k. sangwal. J. crystal Growth 97 (1989) 393

[2]I.OWCZAREK, k. sangwal. J. crystal Growth102 (1990) 574

[3]L.N. Rashkovich, KDP Family of single crystal, Adam Hilger, New York ,1991

[4]J.W.Mullin, crystallization, thirded, Butterworth Hinemann London, 1993

[5]Atlomare.A. cascarano. G. Giacova ZZo.c.Guagliardi,A.Burla.M.c.polidori,G\&Gamali.M(1994)Appl. cryst.27.435

[6]J.Yabuzaki.T.Takahasmi H.Adiuchi Y.Mori, T.sasaki Bull.Mater.science 22 (1999)11-13

[7]G.A. Jeffery. An Introduction to Hydrogen Bonding oxford university press, New York-1997

[8]J.B. Gaudry L. caps. p. Langot s.Marcen, M.kollmannsbergerO.Lavastrte,E.freysh,J.F.Letard,o.skahn,chem. phys.Lett.324 (2000) 321-329

[9]L.M.Epstein,E.s.shubinacoord.chem.Rev, 23 (2002) 165-181s

[10]M.Makowska-Janusika, E.Gondek.I.V.kityk, J.wisla J.sanetra,A.danel,chem..phys.306s (2004) 265-271

[11]Tanusripal.Tanusree kar,Gabriele Bocelli,Lara Rigi,cryst.Growth.Des.3(2003)13

[12]A.datta,s.k.pati,chem..Eur J.11(2005) 4961

[13]L.R.Dalton,P.A.sullivan,B.C.olbricht.D.H.Bale

B.C.Olbricht.D.H.Bale J.Takayesh,s.Hammond H.R0mmel,B.H.Robinson,Tutorials in complex photonic smedia,SPIE,Belingham,WA,2007

[14]. V.krishnakumar,s.kalyaranama,M.piasecki,I.V.KITYK,P.Bragid J.Raman spectrosc,39 (2008)1450-1454.

[15].Ramachandra Raja,A,Antony.Josesh:Mater.Lett.63 (2009) 2507 2509s

[16]Gana sambandam c.perumal s.J.Cryst Growth $2010: 312: 1599$

[17]Nagalakshmi R.krishnakumar V.Hagemann.H.Muthunatesan s.J.Mol structure.2007 832:101

[18]peramiyan G.pandi p.sorna murthy BM.Mohan kumar R.Adv.matter Ros 2012:584:13

[19]k.Boopathi,p.Rajesh,p.Ramasamy.p.Manyum.opt.Mater.35 (2013) 954

[20]A.Arunkumar.p.Ramasamy.Mater.Letter.123 (2014) 246-249

[21]S.karthiga. kalainatahn k. Umameshwara SRao,F.Hamada.M.Yamada.y.kondo.J. cryst. Growth 436 (2016) 11 3-124

[22] R. Dhanjayan N.sivakumar s.Gunasekar s.srinivasan J.Matter.196 (2017) 74-77 